\title{
Is there a need for pelvic ultrasound within integrated sexual health services?
}

\author{
Nicolas Pinto-Sander, Mariam Rela, Kate Yarrow
}

Brighton and Sussex University Hospitals NHS Trust, GU/HIV Department

Royal Sussex County Hospital, Eastern Road, Brighton BN2 5BE, UK. Nicolas.pinto-sander@bsuh.nhs.uk

Introduction: Sexual health services see a large number of women, who once infection is excluded, may require the use of pelvic ultrasound to aid diagnosis and subsequent management. With the integration of many sexual health services across the UK, women often present with primarily gynaecological or reproductive healthcare problems. Without in-house scanning facilities, most of these women end up on a convoluted route involving several appointments across clinical specialities.

Aim: To assess ultrasound referral outcomes from an integrated sexual health service without in-house scanning facilities and determine what could have been managed in-house if scanning facilities were available.

Method: This observational study examined two consecutive years of referrals for pelvic ultrasounds from a busy integrated sexual health service. Information from referrals to radiology were gathered from an imaging database. Indication and outcomes were analysed from scanning reports.

\begin{tabular}{|l|l|l|}
\hline Indication & Number (total: $\mathbf{n = 1 9 0 )}$ & Percentage \\
\hline $\begin{array}{l}\text { Pain (pelvic, adnexal, } \\
\text { dyspareunia) }\end{array}$ & 79 & $42 \%$ \\
\hline $\begin{array}{l}\text { Pain with IUD } \\
\text { Lost IUD/lost threads }\end{array}$ & 19 & $10 \%$ \\
\hline Bleeding problems & 23 & $12 \%$ \\
\hline Worsening PID & 25 & $13 \%$ \\
\hline Possible pelvic mass & 15 & $8 \%$ \\
\hline $\begin{array}{l}\text { Other } \\
\text { - Constitutional }\end{array}$ & 11 & $6 \%$ \\
\hline $\begin{array}{l}\text { (weightloss, fatigue) } \\
\text { - PMB }\end{array}$ & 8 & $4 \%$ \\
\hline Recurrent UTIs & 1 & \\
- Endocervical lesions & 2 & \\
- Subfertility & 1 & \\
\hline Thickened cervix & 1 & \\
\hline Norvical haemangioma & 1 & \\
\hline & 1 & $5 \%$ \\
\hline
\end{tabular}

Table 1 Indications for ultrasound scan

\begin{tabular}{|c|c|c|}
\hline Findings related to indication & Number (total; $\mathbf{n = 1 9 0 )}$ & Percentage \\
\hline $\begin{array}{l}\text { Normal/No further action } \\
\text { - Inc normal coil scans }\end{array}$ & $\begin{array}{l}115 \\
141\end{array}$ & $\begin{array}{l}61 \% \\
74 \%\end{array}$ \\
\hline IUD in situ & 26 & $14 \%$ \\
\hline $\begin{array}{l}\text { Abnormal; requiring action } \\
\text { - Gynaecology } \\
\text { : } \text { ?Polomptrial thickening } \\
\text { - } \text { Dermoid cyst } \\
\text { - } \text { Endometrioma } \\
\text { - } \text { Ovaltiple submucosal fibroids } \\
\text { - IUD penetrating to myometrium } \\
\text { - } \text { Rescan - all ovarian cysts } \\
\text { - GU/SRH - low lying coil } \\
\text { - Surgery - free fluid around appendix }\end{array}$ & $\begin{array}{l}30 \\
20 \\
5 \\
4 \\
4 \\
3 \\
1 \\
1 \\
1 \\
1 \\
8 \\
1 \\
1\end{array}$ & $16 \%$ \\
\hline $\begin{array}{l}\text { Other/incidental findings } \\
\text { - Polycystic ovaries } \\
\text { - } \text { Fibroid(s) } \\
\text { - } \text { Myometrial cyst } \\
\text { - } \text { Adenomyosis } \\
\text { - } \\
\text { Mesenteric cyst above uterus }\end{array}$ & $\begin{array}{l}19 \\
8 \\
7 \\
1 \\
2 \\
1\end{array}$ & $10 \%$ \\
\hline
\end{tabular}

Table 2 Findings from ultrasound scan

Results: 190 patients were referred for a pelvic ultrasound scan over the 2 year period with a mean age of 31(16-69) but the largest proportion were 20-30 years old. 184/190(97\%) were outpatients. 106/190(56\%) had transvaginal scans and 76/190(40\%) had transabdominal and 8/190(4\%) had both. Table 1 shows indications for ultrasound referrals of which 79/190(42\%) were scanned for pelvic pain, and 42/190(22\%) for coil related concerns. Table 2 shows the outcomes of scans of which 141/190(74\%) had normal findings. Of coil related referrals, only $1 / 42(2 \%)$ needed intervention. 19/190(10\%) of pelvic ultrasounds had incidental findings not requiring follow up, and 30/190(16\%) had findings requiring intervention or follow up.

Discussion: In this study, $3 / 4$ of ultrasound scans were normal and could have been managed in-house with scanning facilities/expertise. All coils with "lost threads" were found to be intrauterine - and therefore could also be managed within an integrated sexual health service. Only a small number of those scanned needed onward referral or follow-up. With scanning expertise and resources, patients would be seen more quickly, with a reduction in appointments and fewer referrals. This would result in improved patient satisfaction and reduced costs to the NHS. The set-up costs would be offset in the long-term by keeping patients out of the acute setting.

\section{Conclusions}

- In-house scanning offers the possibility of immediate diagnosis and 'one stop shop' management with a reduction in number of patient visits/referrals.

- Difficulties with setting up an in-house ultrasound service (funding, staffing, ongoing training and clinical governance) would be offset long term by cost savings and improved patient journey/satisfaction.

- Fully integrated sexual health services should be offering in-house ultrasound scanning 